\title{
CAMINHOS CRUZADOS
}

\author{
Rumo a uma estratégia de desenvolvimento \\ baseada na inovação*
}

GLAUCO ARBIX

\section{RESUMO}

Nos últimos quinze anos, novas políticas de Ciência, Tecnologia e Inovação (CT\&I) promoveram avanços institucionais importantes no Brasil.É forçoso reconhecer, porém, que a partir de 2003 há uma inflexão nas políticas públicas de CT\&I. Um novo ativismo de Estado - distinto do dirigismo desenvolvimentista - trouxe para o centro da agenda os processos de inovação, tidos como essenciais para elevar o padrão de competitividade da economia. Há, no entanto, um longo caminho pela frente para que o país assuma uma estratégia de desenvolvimento baseada na inovação.

PALAVRAS-CHAVE: Inovação; ciência e tecnologia; pesquisa e

desenvolvimento; política industrial; ativismo estatal.

\section{ABSTRACT}

Over the last fifteen years, new ST\&I policies have fostered institutional progresses that has put Brazil in an ascendant path. One has to acknowledge, though, that 2003 marks a turning point in ST\&I public policies. A new state activism - distinct from the dirigisme typical of the developmentalist state - has put innovation processes, considered to be crucial for raising Brazil's level of economic competitiveness, in the center of the political agenda. There are, though, further steps to be taken in order to implement a development strategy based on innovation.

KEYWORDS: Innovation; science and technology; research and development; industrial policy; state activism.

[*] Este artigo foi escrito durante estágio de pesquisa no Departamento de Ciência Política do Massachusetts Institute of Technology (MIT, Estados Unidos), em janeiro e fevereiro de 2010, como parte do Fulbright New Century Scholars Program 2009-2010. Registro minha gratidão aos professores Ben Ross Schneider e Richard Locke (MIT) pela calorosa acolhida durante o rigoroso inverno de Boston. Agradeço também à Fundação Fulbright, à Fapesp e ao CNPq pelo apoio às minhas atividades de pesquisa, assim como aos criteriosos comentários do parecerista anônimo desta revista.
Por décadas, a produção de tecnologia e inovação no Brasil foi tratada mais como um subproduto do crescimento econômico do que um prerrequisito para o desenvolvimento econômico e social.

Em linhas gerais, durante o período desenvolvimentista, embora freqüentemente fizessem parte da agenda dos formuladores de políticas públicas, inovação e tecnologia foram tomadas como resultantes naturais do processo de industrialização, que deveria se orientar para a construção de uma economia com empresas dinâmicas e, no limite, inovadoras. No interior desse plano de construção nacional, apesar das diferentes versões que a condução da economia assumiu desde os anos de 1930, as políticas de Ciência e Tecnologia (C\&T) no Brasil voltaram-se prioritariamente para a construção, o a poio e o fortalecimento 
da pesquisa básica, a ser gerada em institutos e universidades e assumida como precondição para possíveis avanços tecnológicos em uma sociedade orientada para a industrialização.

Mesmo com as alterações profundas na elaboração e na condução da economia ao longo dos anos de 1990, as empresas continuaram fora do foco das políticas e dos programas de C\&T, pois o setor produtivo era visto essencialmente como um receptor do conhecimento produzido e dos recursos humanos treinados pela universidade. Ao longo de praticamente toda essa década, o avanço tecnológico substantivo esteve associado ao estabelecimento de um ambiente baseado nos bons fundamentos de uma economia orientada para os mercados. Algumas características básicas do tratamento anterior dado à geração de tecnologia, em que pesem todas as alterações no ambiente econômico e institucional, seriam mantidas: desta vez, a expectativa era que inovação e tecnologia seriam impulsionadas nas empresas a partir do funcionamento mais competitivo dos mercados e da busca de ganhos de produtividade.

No final da década de 1990, e particularmente desde 2004, com a nova Política Industrial, Tecnológica e de Comércio Exterior(PITCE), a inovação passou a ocupar posição de destaque nos planos governamentais e receber tratamento acentuadamente pró-ativo do setor público até sua incorporação explícita na retomada de políticas de desenvolvimento nacional, em especial após a Política de Desenvolvimento Produtivo (PDP) e do Plano de CT\&I (2008).

Nessa nova fase, são fortes os sinais de mudança de rumo, após um longo período de automatismos, incertezas e indefinições: tecnologia e inovação, no reordenamento político em curso, foram captadas pelo radar das políticas públicas e passaram - ainda que lentamente - a receber atenção especial do sistema de incentivos e de financiamento público. Como conseqüência, as empresas começaram a ser vistas e tratadas como unidades-chave para a geração de inovações, e a economia tornou-se mais amigável às empresas inovadoras.

Qual o alcance desses primeiros passos? Representariam uma mudança efetiva de rumo no tratamento da relação entre ciência, tecnologia e desenvolvimento e na consolidação das empresas como alvo prioritário das políticas de inovação?

O presente texto é uma tentativa de iluminar alguns pontos da trajetória recentemente deflagrada no Brasil. Apesar de mostrar maior relevância e qualidade do que a abordagem desenvolvimentista e também dos ensaios de sua superação nos anos de 1990, essa trajetória não possui a forma de uma estratégia claramente definida e explicitada de desenvolvimento. Nesse sentido, o que nos move é menos o interesse pelo novo e mais a necessidade imperiosa de elevar o padrão de competitividade da economia brasileira, o que, acreditamos, não será alcançado se as políticas públicas de apoio ao 
fortalecimento das empresas não se distanciarem tanto do dirigismo estatal que marcou o desenvolvimentismo até os anos de 1970, como da inação dos anos de 1990.

As mudanças institucionais, em especial as de C\&T, são lentas principalmente por causa das dificuldades inerentes a todo processo de longa maturação. A fragmentação política do Estado para elaborar e consolidar diretrizes claras de políticas industriais e de inovação, assim como os conflitos no governo, a tensão entre ministérios e o imediatismo que muitas vezes marca o mundo empresarial persistem como obstáculos para a identificação das novas demandas e para a experimentação de novos modelos de fomento à inovação no setor privado.

Os processos de inovação são essenciais e insubstituíveis para elevar o padrão de qualidade da economia brasileira, seja para a ampliação e a dinamização do mercado interno, seja para a diversificação e a construção de uma nova inserção internacional. Apesar dos avanços políticos, legais e institucionais nos últimos anos, no entanto, a economia brasileira tem um longo caminho pela frente antes de se tornar realmente mais acolhedora e estimuladora da inovação, em termos de ambiente, incentivos, instituições e instrumentos.

A reflexão a seguir busca: (i) rastrear a evolução de escolhas relacionadas com o desenvolvimento através da lente das políticas de C\&T; (ii) discutir o avanço recente - e promissor - em direção a novas políticas com foco na inovação; (iii) apontar algumas insuficiências e fraquezas, e discutir a necessidade de expansão e diversificação do sistema nacional de Ciência, Tecnologia e Inovação. Não temos intenção - nem condições - de analisar a execução de programas e seus impactos. O objetivo é realçar as principais inflexões de políticas, assim como os pontos substantivos relacionados com a reorganização institucional que ganhou força a partir do final dos anos de 1990. Como conclusão, a sugestão destacada é a criação de uma Agência Nacional de Inovação, ligada à presidência da República.

\section{DO LEGAdO deSENVOLVIMENTISTA À LIBERALIZAÇÃo CEGA}

Durante o período desenvolvimentista, basicamente entre 1940 e o final da década de 1970, o estilo centralizado de planejamento estatal respondeu pela elaboração e definição de um conjunto de políticas prescritivas, como regulamentação monetária, níveis e segmentação de impostos, assim como a alocação do investimento público, subsídios e incentivos. As políticas protecionistas ocuparam lugar proeminente no dispositivo de atuação de um Estado institucionalmente orientado para apoiar a industrialização tomada como veículo para a modernização. $O$ ponto central a ser equacio- 
nado dizia respeito à internalização de capacidade industrial (com destaque para a indústria pesada) e de processos de manufatura em geral que o Brasil não controlava nem dominava. Competitividade e tecnologia seriam alcançadas à medida que o incipiente tecido produtivo avançasse na elevação de seu padrão e se tornasse mais complexo e integrado. Nesse estilo de modernização movida e induzida pelo Estado, os processos tecnológicos e de inovação nas empresas foram efêmeros e raramente alcançaram profundidade. Movimento semelhante ocorreu em praticamente toda a América Latina. Em países como Brasil, México e Argentina, as três maiores economias do continente, governos nacionalistas sustentaram políticas de industrialização no intuito de superar sua alta dependência de produtos primários ou intensivos em recursos naturais.

A crise de 1929 e a conseqüente desorganização da economia mundial levaram os Estados a se reposicionarem de modo a controlar e disciplinar os mercados e a interferir mais enfaticamente na economia como um todo. O impacto foi especial no mundo em desenvolvimento. No Brasil, mecanismos de proteção e de subsídios para a indústria nascente combinaram-se com incentivos fartos orientados para atração de corporações e investimento estrangeiros. Após a Segunda Guerra Mundial, novas medidas, instrumentos e instituições seriam implantadas de modo a conformar uma estratégia mais consistentes de desenvolvimento. A Companhia Siderúrgica Nacional (CSN) e a Companhia Hidroelétrica do São Francisco (Chesf) foram criadas pelo Estado brasileiro como parte do esforço de industrialização. Somaram-se à Fábrica Nacional de Motores (FNM) è̀ Petrobrás e passaram a funcionar como apoio e sustentação do desenvolvimento brasileiro.

Empresas públicas, protecionismo econômico e incentivos estatais articularam-se com o capital e as corporações estrangeiras na expectativa de emular a industrialização e estimular o nascimento de empreendedores e de empresas genuinamente nacionais. Essa articulação desempenhou papel central na sustentação das políticas de Substituição de Importações (SI), que tinham no seu ponto de partida a rejeição de um suposto lugar natural a ser ocupado pelos países de industrialização tardia na economia mundial. A fraqueza estrutural da indústria na América Latina, assim como suas dificuldades em "confrontar-se com o interesse dos exportadores de bens primários", tornou ainda mais evidente a necessidade do Estado em sustentare impulsionar o desenvolvimento.

Baseadas em Prebisch ${ }^{2}$ e nas reflexões da Cepal, as políticas de SI - ou políticas de "industrialização dirigidas pelo Estado", no dizer de Ocampo 3 - disseminaram-se pelo continente latino-americano e firmaram-se como um meio para: (i) absorver competências; (ii)
[1] Hirschman, A. O. "The political economy of import-substituting industrialization in Latin America". The Quarterly Journal of Economics, 1968 , vol. $82, n^{\circ}{ }_{1}$, pp. 1-32, p. 28.

[2] Prebisch, Raúl. "Interpretación del proceso de desarrollo latinoamericano em 1949". Serie Conmemorativa del XXV Aniversario de la Cepal. Santiago: Cepal, 1973.

[3] Ocampo, José Antonio. "La América Latina y la economía mundial en el largo siglo XX". El Trimestre Económico, 2004, vol. LXXI (4), $\mathrm{n}^{\circ}$ 284, out.-dez., pp. 725-86, p.3. 
[4] A esse respeito, ver Rosenberg, N. "Economic experiments". In: Exploring the blackbox. Cambridge: Cambridge University Free Press, 1994; Aghion, P., Dewatripont, M.e Stein, J. “Academic freedom, privatesector focus, and the process of innovation". Rand Journal of Economics, 2008, vol. $39, n^{\circ} 3$, pp. $617-35$.

[5] Romer, P. The arc of science. Palo Alto, California: Stanford University, 2005 (mimeo.).

[6] Vermulm, R. e De Paula, T. “A política tecnológica no Brasil e a experiência internacional". Relatório Iedi, 2006. captar tecnologia estrangeira; (iii) promover a industrialização como pré-condição para o desenvolvimento; (iv) reduzir a pobreza e a desigualdade como resultado do crescimento econômico.

Nesse quadro, a melhoria tecnológica era vista como o resultado natural da industrialização dirigida pelo Estado. A capacitação e a elevação do padrão produtivo seriam obtidas diretamente por meio da absorção de técnicas e habilidades da manufatura estrangeira ou, indiretamente, surgiriam do transbordamento (spillover) e de efeitos colaterais do movimento de industrialização intensiva e extensiva.

No Brasil, esse modelo previa que a transferência de tecnologia seria realizada via corporações multinacionais. Para viabilizar e sustentar os processos de absorção de conhecimento e de competências, o Estado passou a investir na construção de um sistema universitário orientado para o desenvolvimento de pesquisa básica. A expectativa era que as empresas privadas nascentes seriam capazes de integrar tanto as técnicas estrangeiras quanto o conhecimento gerado pelas universidades, de modo a se tornarem capazes de desenvolver sua própria dinâmica de Pesquisa e Desenvolvimento (P\&D) com geração de tecnologia.

O reconhecimento do impacto real dos fluxos de transferência de tecnologia das multinacionais para firmas nacionais nesse período é uma tarefa ainda por ser feita no Brasil. Na mesma chave, a reduzida apropriação pelo setor privado do conhecimento produzido pela Universidade brasileira foi uma das razões que levaram à criação de duas novas instituições, o Conselho Nacional para o Desenvolvimento Científico e Tecnológico (CNPq) e a Coordenação de Aperfeiçoamento de Pessoal de Nível Superior (Capes), em 1951, e que representou um ponto de inflexão na história da C\&T no Brasil.

As duas entidades, entretanto, baseavam-se em idéias predominantes na época e que sustentavam o modelo linear4 como o fundamento da geração de inovação. Grosso modo, esse modelo pressupunha que o conhecimento deveria seguir uma linha de continuidade entre a pesquisa básica até chegar às empresas e aos mercados, a partir da geração de inovações.

Estudos realizados em economias avançadas identificaram sistematicamente várias distorções criadas pelo modelo linear no relacionamento entre universidade e empresa5. Em países como o Brasil, com indústria incipiente, baixo nível de empreendedorismo, de investimento e inovação, a versão tropicalizada do modelo linear contribuiu tanto para o isolamento da universidade e da comunidade acadêmica, como para a consolidação de fortes preconceitos no meio empresarial ${ }^{6}$

Contrariando as expectativas positivas sobre a eficácia do modelo linear, as empresas nascentes beneficiaram-se apenas parcialmente do conhecimento gerado pelas universidades e centros de pesquisa. 
Nem mesmo a fundação do Senai em 1942, destinado a treinar a força de trabalho industrial, conseguiu amenizar a concentração das atenções do Estado na educação superior. A hipótese dos planejadores públicos era que o crescimento econômico agiria na base da economia e empurraria todo o sistema educacional na direção de uma crescente qualificação. A história provou-se outra, contudo. A educação de massa ficou para trás, assim como os objetivos mais importantes de todo processo de desenvolvimento — a redução da pobreza e das desigualdades sociais.

A desarticulação do sistema de formação e qualificação de recursos humanos, assim como a dissociação entre a pesquisa básica e a necessidade das empresas privadas mutilaram a estrutura brasileira nascente que, dessa forma, não pode absorver nem produzir conhecimento suficiente para dar origem a um sistema endógeno de tecnologia, a não ser em poucos nichos e com impacto apenas residual. A criação das instituições Embrapa, Finep, Inpi, Inmetro, Inpe, entre outras, já na fase final do desenvolvimentismo, não conseguiu amenizar essa realidade. A relação distante e dissociada (em muitos domínios, quase paralela) sobreviveria por décadas e, apesar de avanços, permaneceria, ao longo do tempo, como uma armadilha a ser desarmada.

O Brasil colheu resultados mistos da política desenvolvimentista centralizada no Estado. Se o sistema de SI conseguiu estabelecer uma indústria diversificada e integrada, bem como promover o crescimento econômico acelerado, socialmente, porém, produziu e reproduziu ao lado da pobreza imensa uma trama perversa de desigualdades de toda ordem. Com fina ironia, Hirschman apontou para os limites do modelo de desenvolvimento: "Esperava-se que a industrialização transformasse a ordem social, mas tudo o que fez foi produzir bens manufaturados!"7. E, ainda assim, o modelo brasileiro produziu uma indústria extremamente dependente de proteção e com baixa capacidade de inovação tecnológica.

Nessas condições, os ganhos de produtividade mostravam-se insuficientes para impulsionar e manter o desenvolvimento no longo prazo. No final dos anos de 1970 , os sinais emitidos pela desarticulação do modelo de economia fechada evidenciavam sua insustentabilidade. O peso da dívida externa e a crise do petróleo encarregaram-se de selar a desestruturação do sistema de SI, tal como foi implantado no Brasil e em toda a América Latina.

A reação dos planejadores públicos e do empresariado não se voltou, porém, para o questionamento da armadilha tecnológica que marcou a matriz da política desenvolvimentista. Ao pesquisar a experiência latino-americana, Schrank e Kurtz compararam diferentes modalidades de política industrial e concluíram: 
[8] Schrank, A. e Kurtz, M. "Credit where credit is due: open economy industrial policy and export diversification in Latin America and the Caribbean". Politics Society, 2005, vol. $33, \mathrm{n}^{\circ} 4$, pp. 671-702, p. 683 .

[9] North, D. Institutions, institutional change, and economic performance. Cambridge: Cambridge University Press, 1990, p. 6.
[...] enquanto as tarifas e o controle das importações forem concebidos para estimular o crescimento da indústria nascente, seus filhotes tenderão a buscar o conforto do seio materno e não o enfrentamento da dura realidade da economia internacional - dessa forma, estarão inclinados a transformarse em adolescentes problemáticos, caros e exigentes. Como empresas, serão economicamente frágeis, ainda que politicamente fortes. Nessas condições, pressionarão o Estado em busca de maior apoio, em detrimento da sua especialização, investimento e fortalecimento ${ }^{8}$.

Aênfase no círculo vicioso revelado pelos autores ajuda-nos a identificar os pontos nevrálgicos do debate, freqüentemente minimizados.

Os sinais de formação de um novo cenário internacional com a presença de cadeias globais de valor alimentadas por intensos fluxos de conhecimento já estavam à mostra nos anos de 1970. Mesmo assim, a reação dos setores público e privado no sentido de repensar e reestruturar o modo de funcionamento e os pilares da economia brasileira foi tão tímida quanto tardia. Dado o enraizamento de práticas e interesses, o debate sobre eventuais mudanças foi traumático nos órgãos estatais e no meio empresarial. Após décadas de relativo sucesso de um modelo de crescimento baseado na valorização do investimento em capital fixo numa economia altamente protegida, o desenho de alternativas que privilegiariam os bens intangíveis e inovadores - embebidos de conhecimento - aparecia como uma guinada radical de rumo, impraticável para muitos. Nos momentos de mudança das "regras do jogo", no dizer de North', as estruturas de produção e as redes de relações sociais e políticas tendem a se fechar e a resistir, mesmo percebendo-se em declínio, como se a preservação de hábitos e relações especiais de competição fosse condição de sua sobrevivência.

A busca por um novo modelo de desenvolvimento e de política industrial enfrentava um obstáculo maior, consubstanciado no que chamamos de obsolescência institucional. Ou seja, estruturas que se mostraram apropriadas para os primeiros estágios do desenvolvimento brasileiro tornaram-se inadequadas para organizar, favorecer e orientar uma economia mais madura, cuja heterogeneidade e diversificação esbarravam nos limites de uma economia rigidamente disciplinada pelo Estado. Se adicionarmos à análise os obstáculos estruturais ligados à infra-estrutura e à instável conjuntura de crise do início dos anos de 1980, estaremos em melhores condições para dimensionar as dúvidas que atormentavam os planejadores e os formuladores de políticas públicas na época. O que adaptar? O que abandonar? O que construir? Em que medida a necessária transição poderia ser feita sem que provocasse (ou acelerasse) a degradação das estruturas de Estado? Até que ponto essa travessia poderia ser 
realizada em meio à crise da dívida externa, aos choques do petróleo e aos fortes constrangimentos fiscais que minavam a capacidade de intervenção pública?

$\mathrm{Na}$ raiz dessas interrogações encontravam-se os dilemas de um Estado acostumado a se apresentar como um exemplo de industrialização bem-sucedida, mas que agora penava para se orientar diante do leque de opções - ou adaptações - supostamente mais adequadas para ambientes econômicos mais abertos, com finanças, comércio e alocação de investimentos menos controlados. Do ponto de vista microeconômico, as alternativas pressupunham um universo corporativo mais ágil e dinâmico, baseado em processos de gestão avançados, mais apropriados para enfrentar a competição em mercados em que os mecanismos de controle de preços tendiam a diminuir.

As respostas do setor público e do empresariado apenas a contagotas desenvolveram-se na direção de um reordenamento institucional com ênfase nas atividades intensivas em conhecimento, no (re) equacionamento do sistema de P\&D e na reestruturação e requalificação da educação nacional. Tardias - e, na maior parte das vezes, conservadoras - as reações, em geral, contribuíram para a sobrevivência de instituições ineficientes em um ambiente já pressionado pela rápida expansão de novos padrões tecnológicos e práticas econômicas que se manifestaram nos países avançados. A emergência de novos paradigmas produtivos e tecnológicos sacudiu os pilares de sustentação da segunda revolução industrial ${ }^{10}$, acarretando conseqüências desagregadoras para países de industrialização recente como o Brasil.

A rápida difusão da microeletrônica e das tecnologias da informação e comunicação expôs os limites da industrialização brasileira que havia se aproximado, como num processo de catching up, da modernidade industrial. Porém, mesmo embalada pelo esforço de dois Planos Nacionais de Desenvolvimento (PNDs), com destaque para o segundo, a elevação do patamar de diversificação da indústria brasileira, embora importante, mostrava-se insuficiente. Em desvantagem tecnológica, seja nos seus atributos, seja em capacidades competitivas, a indústria distanciava-se, mais uma vez, da fronteira tecnológica.

Além de difíceis, pois pressupunham redirecionar o país para um novo estilo de desenvolvimento, muitas das escolhas eram contraditórias. Exatamente por isso, o entendimento dos processos de envelhecimento e inadequação institucional, em todas as suas características e sutilezas, era - e continua sendo - ponto essencial para o delineamento de novos rumos para o país.

A busca de novos caminhos - busca essa apenas sinalizada no final da década de 1970 - marcaria os 25 anos seguintes e atualizaria muitos dos dilemas e das armadilhas que se manifestaram no período final do ciclo desenvolvimentista. O preço, econômico e social, seria
[10] Freeman, C. Systems of innovation: selected essays in evolutionary economics. Cheltnham: E. Elgar, 2008. 
alto - baixo crescimento, alto desemprego e aumento da pobreza como era de se esperar para um país que voltou a se distanciar das nações avançadas, em que pese seu esforço de crescimento por meio da industrialização, sem foco na tecnologia, na inovação e na educação.

Uma das primeiras tentativas mais consistentes de mudança de rumo viria à tona com Fernando Collor de Mello, o primeiro presidente eleito democraticamente após mais de 25 de autoritarismo. $\mathrm{O}$ diagnóstico subjacente apontava para uma necessária abertura da economia, ainda que, em muitos sentidos, o Estado era apontado como o principal responsável pela estagnação econômica. A desconstrução do modelo de SI foi assumida como o principal objetivo político e institucional do governo Collor de Mello, embora tenha sido explicitada como estratégia pelo governo de Fernando Henrique Cardoso. Com a liberalização e os processos de privatização, o Estado já fragilizado, dada sua precária condição fiscal, seria ainda mais constrangido em seu poder estruturante.

Mudanças institucionais foram introduzidas de modo a combinar um maior trânsito dos agentes privados com mecanismos de contenção da atuação estatal, tida como o grande obstáculo ao desenvolvimento. O rígido sistema regulatório estatal, a propriedade pública de empresas e o controle sobre setores inteiros da economia e seu viés protecionista deveriam ser desmontados - ou ao menos diminuídos substancialmente - para abrir espaço aos mercados, às empresas e ao investimento privado. Intervenções de cunho desenvolvimentista foram consideradas ultrapassadas e nocivas ao país. Os altos níveis de ineficiência e de atraso tecnológico foram atribuídos às políticas públicas, em geral, com viés contrário à livre competição.

No plano político, o processo de desenvolvimento passou a ser tratado no âmbito de um continuum - em que um sistema protecionista e o Estado despontavam como pilares essenciais - , cuja direção precisava ser drasticamente alterada, rumo a um modelo voltado para fora, baseado no funcionamento mais livre dos mercados. Nesse novo sistema, as políticas industriais e de desenvolvimento, em suas várias versões, eram consideradas idéias fora de lugar. A conduta rígida da política macroeconômica desencorajou medidas pró-ativas dirigidas para a elevação de nível de competitividade da economia. $\mathrm{O}$ mote anunciado pelo então ministro da Fazenda, Pedro Malan - "A melhor política industrial é não ter política industrial" - tornou-se a marca registrada de toda uma era. A abertura e a liberalização da economia seriam tomadas como o primeiro motor da eficiência e da evolução tecnológica, combinadas à diminuição do protecionismo e ao aumento da competição.

De fato, entre as recomendações da ortodoxia econômica, o termo eficiência seria drenado de suas relações com a tecnologia. Nesse 
contexto, a atividade pública foi orientada para o investimento em infra-estrutura e para a formação de recursos humanos, como meio indireto de ajudar na elevação do padrão tecnológico. Desse ângulo, a despeito das dificuldades fiscais, houve avanços na área de recursos humanos para C\&T no sistema brasileiro de pós-graduação e no sistema educacional, que vivenciaram expansão significativa ao longo dos anos de 1990.

No que se refere à inovação, em especial no interior das empresas, a liberalização mostrar-se-ia absolutamente insuficiente. Mais ainda, tenderia a reproduzir uma visão desfocada da inovação e da tecnologia, agora tomadas como fruto da competição numa sociedade aberta. A abordagem, em que pesem os sinais contrários, era de natureza similar à formulada pelo desenvolvimentismo, quando inovação e tecnologia foram vistas como subproduto do crescimento econômico. Nas duas concepções, a lógica própria do desenvolvimento tecnológico e dos processos inovadores foi diluída, e o reforço de sua dinâmica - por meio de políticas especialmente concebidas para esse fim - , substituído pelo desempenho e interferência de fatores externos às empresas e distantes dos mecanismos efetivos de geração da inovação e da tecnologia.

Os resultados colhidos durante a década, no entanto, não deram motivo para otimismo. A distância que separava o Brasil das práticas tecnológicas mais avançadas - especialmente as derivadas dos avanços na microeletrônica e nas tecnologias da informação e comunicação - aumentou consideravelmente nos anos de 1990.

Foi apenas no final do segundo mandato de Fernando Henrique Cardoso, como resposta às pressões pela revitalização das instituições de C\&T, enfraquecidas por sucessivas restrições orçamentárias, que o debate sobre inovação e tecnologia ganhou maior atenção. A atuação do governo, em especial do Ministério da Ciência e Tecnologia (MCT), foi decisiva para a criação dos Fundos Setoriais, que mudaram para melhor o sistema nacional de financiamento à inovação. Por seu arrojo e engenhosidade institucional, provavelmente a criação dos Fundos Setoriais no Congresso possa ser reconhecida como o passo mais importante dado ao longo do segundo mandato do governo FHC, exatamente por responder positivamente ao déficit institucional e à inadequação dos mecanismos de financiamento do período anterior.

Mesmo com o estabelecimento desse novo sistema - fundamental para viabilizar avanços no sistema de inovação alcançados posteriormente - a ruptura com o viés das políticas de C\&T do passado foi apenas parcial: os processos de financiamento da inovação, apesar de contarem com mecanismos mais sofisticados, continuaram orientados primordialmente para as universidades públicas e os institutos de pesquisa. De um ponto de vista mais geral, o modelo linear - que 
pressupunha a concentração dos investimentos na pesquisa básica como condição para a inovação - mostrava-se exuberante no interior das instituições brasileiras responsáveis pela CT\&I.

\section{A VIRADA do sÉculo}

No governo Luiz Inácio Lula da Silva, o Estado e suas instituições foram mais pró-ativas do que nos anos de 1990. A preocupação com as políticas industriais foi reintroduzida no debate público sobrecrescimento, em companhia da proposta de construção de um projeto nacional de desenvolvimento. No início de 2004, o governo anunciou a Política Industrial, Tecnológica e de Comércio Exterior (PITCE), após mais de 25 anos sem diretrizes globais nesse terreno. Apesar de seu rótulo - política industrial - relembrar práticas passadas, ou de algumas fraquezas explícitas - como a precária abordagem da questão regional - , a PITCE foi elaborada de modo a orientar a economia para capacitar-se nas áreas mais intensivas em tecnologia e conhecimento, única maneira de sustentar o crescimento no longo prazo. Para evitar as armadilhas do passado, a PITCE estabeleceu o foco de sua abordagem nos processos de inovação e orientou seus esforços para a capacitação das empresas. Os fundamentos que nortearam a elaboração dessa política foram:

1. As políticas industriais do presente são essencialmente diferentes de experiências passadas, e devem ser orientadas para a inovação.

2. Não resta muito espaço para o protecionismo sistêmico nem para o desenvolvimento em economia fechada. Nesse sentido, a intervenção do Estado no século XXI deve ser distinta das práticas do ciclo desenvolvimentista.

3. A elevação do padrão da economia - principalmente dos processos de geração e absorção tecnológica e de inovação - deve ocupar o centro das preocupações das políticas públicas, em conjunto com o investimento em infra-estrutura e no sistema educacional.

4. O velho Estado desenvolvimentista está morto; o que não significa que o Estado esteja em declínio. É certo que perdeu a capacidade de definir isoladamente as políticas industriais necessárias para promover aumento de competitividade, mas não perdeu a capacidade de construir - e repensar - instituições e de promover novas interações entre os setores público e privado.

5. Diferentemente do passado, as mudanças em curso no Brasil estão assentadas numa democracia madura, o que favorece o diálogo entre o Estado e a sociedade, permitindo a mobilização dos 
agentes econômicos e a transparência indispensável para um amplo debate sobre objetivos, prioridades e duração dos incentivos.

A PITCE, longe de constituir-se em fato isolado, foi acompanhada de um conjunto de decisões realizadas pelo poder público. O Quadro 1 registra alguns pontos de inflexão na trajetória da C\&T nos últimos anos. Sua construção, inspirada por algumas sugestões de Freeman ${ }^{11}$, orientou-se pelo seguinte roteiro: (i) [11] Ibidem. adoção, imitação, aperfeiçoamento e desenvolvimento de novas ferramentas e técnicas de produção; (ii) geração de conhecimento novo; (iii) sistema de inovação econômica (incentivos, produção e distribuição de bens e serviços); (iv) instituições políticas e regulatórias; (v) valores e costumes.

\section{QUADRO I}

Diretrizes legais, novos instrumentos e programas de C\&T\&I (1994-2009)

\begin{tabular}{|c|c|c|}
\hline & Década de 1990 & 2003-2009 \\
\hline Política de Inovação & Primeiros passos & $\begin{array}{c}\text { PITCE }-2004^{\mathrm{a}} \\
\text { PDP }-2008^{\mathrm{b}} \\
\text { PAC-C\&T }-2008^{\mathrm{c}}\end{array}$ \\
\hline Criação de uma nova estrutura legal & $\begin{array}{c}\text { Lei de Proteção da Concorrência (1994) } \\
\text { Lei de Informática (2001) } \\
\text { Dedução em dobro no IR e CSLL dos gastos em P\&D } \\
\text { Lei de Propriedade Industrial }\end{array}$ & $\begin{array}{c}\text { Lei de Inovação (2004) } \\
\text { Lei do Bem }(2005)^{\mathrm{d}} \\
\text { Lei de Biossegurança (2005) } \\
\text { Lei de Informática }\end{array}$ \\
\hline Novas Instituições & $\begin{array}{c}\text { Agências Reguladoras } \\
\text { Criação Fundos Setoriais } \\
\text { CGEE }^{g}\end{array}$ & $\begin{array}{c}\text { ABDI }(2004)^{e} \\
\text { CNDI }(2004)^{f} \\
\text { INCTs (123 no país) }\end{array}$ \\
\hline BNDES e Finep & $\begin{array}{c}\text { Privatização } \\
\text { Projeto Inovar (capital risco) }\end{array}$ & $\begin{array}{c}\text { Iniciativa Tecnológica }^{\mathrm{h}} \\
\text { Empreendedorismo Empresarial } \\
\text { Criatec } \\
\text { Pró-Inovação } \\
\text { Subvenção Econômica } \\
\text { Programa de Venture Capital }\end{array}$ \\
\hline Novos instrumentos setoriais & $\begin{array}{l}\text { Regime automotivo (1995) } \\
\text { Lei da Informática }\end{array}$ & $\begin{array}{l}\text { Prominp (Petrobrás) } \\
\text { ProSoft expandido } \\
\text { ProFarma } \\
\text { Sibratec }\end{array}$ \\
\hline
\end{tabular}

a Política Industrial, Tecnológica e de Comércio Exterior (PITCE, 2004); b Política de Desenvolvimento Produtivo; c Plano de Ciência e Tecnologia; d Incentivos fiscais para empresas exportadoras (Lei do Bem, 2005); ${ }^{\mathrm{e}}$ Agência Brasileira de Desenvolvimento Industrial (ABDI, 2004); ${ }^{\mathrm{f} C o n s e l h o ~ N a c i o n a l ~ d e ~ D e s e n v o l v i m e n t o ~}$ Industrial (CNDI, 2004); g Centro de Gestão e Estudos Estratégicos; h Funtec, Institutos Nacionais de Ciência e Tecnologia (INCT). 
[12] "As políticas públicas começaram a ampliar sua abordagem de modo a explorar sinergias potenciais entre a promoção de $\mathrm{C} \& \mathrm{~T}$, apoio à $P \& D$ e promoção do comércio e da competitividade" ("Science, technology and industry, Outlook 2008: profile of Brazil". Paris: OECD, 2008, p. 164).

[13] National Science Board. "Science and engineering indicators". Arlington, Virginia: National Science Foundation, 2010, pp. 10101, pp.10-11.

[14] Ibidem, p.11.
[15] De Negri, J. “Trade, innovation and firm growth in Brazil: technology transfer through trade". Paper apresentado no Global Forum on Trade Innovation and Growth (OECD), Paris, out. 2009 (mimeo.)
A multiplicação de iniciativas no campo da inovação, assim como os avanços na área de suporte à geração, no volume do investimento e número e na qualidade dos instrumentos de incentivo à C\&T tornaram-se possíveis graças à continuidade das macropolíticas públicas para essa área.

O debate público realizado por ocasião da IVConferência Nacional de Ciência e Tecnologia, realizada em maio de 2010, em Brasília, confirmou a percepção de uma série de avanços que ocorreram em várias dimensões das atividades ligadas à CT\&I. Em que pesem imprecisões na coleta e formação de indicadores, instituições internacionais como a OCDE ${ }^{12}$, assim como o National Science Board, dos Estados Unidos, começaram a reconhecer eventuais avanços da CT\&I no Brasil, apesar de eventuais diferenças em relação aos dados do MCT. O relatório intitulado "Indicadores de ciência e engenharia", lançado neste ano de 2010 , registra:

Tanto a Índia como o Brasil situam-se entre os países de maior desempenho em CET no mundo, embora não participem do sistema estatístico da OCDE. De acordo com as estatísticas da Unesco, a Índia investiu US\$15 bilhões em CET em 2004 (valores em dólar americano, PPA) e o Brasil investiu US $\$ 13$ bilhões em CET em 2005. Ambas as cifras representamo dobro dos níveis de desempenho em CET que esses países registraram em meados da década de 1990. Esses níveis de investimento em CET colocam a Índia e o Brasil na lista dos 15 maiores investidores do mundo CET ${ }^{13}$.

De acordo com o mesmo relatório, o Brasil também se destacou como um dos mais importantes produtores de artigos científicos, saltando da " $23^{\text {a }}$ posição no ranking de 1995 para a $16^{\text {a }}$ posição em 2007"14. O National Science Board também assinalou que o Brasil ocupa a primeira posição na América Latina, com uma taxa de crescimento anual de produção de artigos científicos de 10,9\% por ano, seguido pelo México (6,7\%), Chile (5,8\%) e Argentina (4,6\%).

Se acompanharmos os dados das principais instituições responsáveis por C\&T no Brasil, poderemos seguir essa trajetória de forma mais clara.

Há uma clara evolução nesse sentido, apesar do longo caminho que precisa ser percorrido para o país alcançar efetivamente um novo patamar na geração e na difusão de CT\&I. Por exemplo, mesmo que pesquisas recentes apontem que as empresas inovadoras pagam salários acima da média da indústria; que seus empregos exigem $20 \%$ a mais de educação do que os gerados pelas demais empresas; e que a média de estabilidade de seus funcionários é cerca de $30 \%$ mais alta que a média geral15, o IBGE registra que apenas cerca de $30 \%$ das empresas industriais brasileiras fazem inovação de produto ou de processo, 
índice não somente menor do que a média dos países avançados, mas abaixo de concorrentes diretos do Brasil como a China.

Estudos do Ipea ${ }^{16}$ mostraram que a competitividade da economia brasileira depende diretamente das vantagens adquiridas a partir da capacitação tecnológica das empresas e do incentivo dado pelos sistemas de inovação. Os investimentos na geração de conhecimento novo, principalmente os relativos a $P \& D$, tendem a ser fortemente pró-cíclicos e a aumentar de acordo com a melhoria do desempenho econômico. O crescimento do PIB brasileiro nos últimos anos encorajou muitas empresas a aumentar significativamente os investimentos em P\&D. Dados levantados por De Negriin ${ }^{17}$, por exemplo, indicam que somente o investimento de empresas líderes responderam por um volume equivalente a US $\$ 5$ bilhões, ao longo do ano de 2008.

Com base na Lei da Inovação ${ }^{18}$ e na Lei do Bem ${ }^{19}$, vários instrumentos foram criados para apoiar a inovação nas empresas, como: (i) incentivos fiscais a P\&D com implementação automática pelas empresas, sem aprovação do MCT; (ii) subsídio para projetos de desenvolvimento tecnológico; (iii) subsídio para alocação de pesquisadores em empresas; (iv) financiamento para "capital de risco" em inovação.

Apesar de seu caráter ainda em grande parte unificador de planos e projetos previamente existentes, a elaboração do Plano Nacional de Ciência, Tecnologia e Inovação, 2007-2010 (chamado de PACCT\&I), anunciado em novembro de 2007 , representou um passo a frente, seja pelo esforço de unificação de várias instituições, programas e orçamentos, seja pela sinalização política da necessidade de se refletir globalmente sobre os desafios da CT\&I no Brasil. O Plano direcionou recursos para investimento e ajudou a triplicar o orçamento do MCT e a elevar os investimentos globais em CT\&I de $0,9 \%$ (2002) para estimados 1,4\% no final deste ano de 2010 , em relação ao PIB. O Plano também estabeleceu quatro prioridades nacionais: (i) expansão e fortalecimento do Sistema Nacional de CT\&I; (ii) promoção da inovação tecnológica nas empresas; (iii) pesquisa, desenvolvimento e inovação em áreas estratégicas; e (iv) ciência, tecnologia e Inovação para o desenvolvimento social. Foi a primeira vez que um plano de estímulo à C\&T, tema especialmente atraente e caro para a comunidade acadêmica, fixou entre suas principais prioridades o apoio à inovação em empresas ${ }^{20}$. Nessa mesma direção, o programa de Subvenção Econômica para Empresas Inovadoras, criado em 2006 e coordenado pela Finep, já apoiou mais de 2 mil empresas e mostrou que, se expandido e aperfeiçoado, poderá ocupar um lugar especial na elevação do nível da competitividade da economia brasileira.
[16] De Negri (coord.). "Relatório de pesquisa sobre inovação tecnológica nas empresas industriais brasileiras". Brasília: Ipea, 2007.

[17] De Negri, "Trade, innovation and firm growth in Brazil", op. cit.

[18] Lei ${ }^{\circ}{ }^{0} 10.973 / 2004$.

[19] Lei no ${ }^{\circ} 11.196 / 2005$. 
Os avanços recentes são significativos, não só em termos de políticas, mas também no volume de investimentos e na diversificação de instrumentos e instituições. Seriam, no entanto, suficientes ou claros em seus objetivos para indicar uma mudança duradoura e de qualidade na condução das políticas de CT\&I?

Os sinais, no entanto, ainda não se manifestaram nitidamente. Há indícios de que a economia brasileira está mais preparada e qualificada, como os emitidos pela emergência de multinacionais brasileiras que disputam mercados mais desenvolvidos. Mas até que ponto o país avançou para uma fronteira superior, de modo que, mesmo que ainda não realizada, a possibilidade de uma aproximação da média dos países da OCDE possa ao menos ser visualizada?

A aceleração do crescimento econômico nos últimos anos foi possibilitada basicamente pelo desempenho da demanda interna, com destaque para a produção industrial, extrativa e o agronegócio. As novas fontes de petróleo no pré-sal, combinadas à competitividade ainda imbatível do etanol brasileiro (que alimenta uma indústria automotiva que produz mais de $90 \%$ de híbridos por ano), os aqüíferos e a extensa biodiversidade, além de abrir ao país novos horizontes, conferem ao governo e às empresas brasileiras enorme vantagem em termos de poder de compra, negociação e comércio.

Se definirmos "alcançar" (catching up) como a habilidade para competir baseada no preço dos produtos de exportação, a lista dos setores e das áreas que evoluíram no Brasil seria extensa. Em muitos segmentos, a participação brasileira no comércio internacional cresceu rapidamente, como na indústria de aviões, do petróleo, na agricultura e mineração. Alcançar, nesse sentido, indica acúmulo de capacidade produtiva. Porém, quando nos referimos a catching up nesse texto, projetamos um movimento mais amploe ambicioso, relativo à transição de uma estrutura que produz para

[21] Bell, M. e Albu, M. "Knowledge systems and technologicaldynamism in industrial clusters in developing countries". World Development, 1999 vol. $27, \mathrm{n}^{\circ}$ 9, pp. 1715-34; Ariffin, N.e Figueiredo, P. "Internacionalisation of innovative capabilities: counterevidence from the electronics industry in Malaysia and Brazil". Oxford Development Studies, 2004, vol. 32, $\mathrm{n}^{\circ}$ 4, pp. 323-62. uma economia capacitada para a inovação ${ }^{21}$. Embora essa distinção encerre problemas - uma vez que os dois termos podem ser relacionados num continuum - , seu uso pareceu-nos adequado para apontar questões de fundo a serem superadas caso o Brasil queira, seriamente, desafiar as economias-líderes a partir da redução do atual gap tecnológico.

Desse ponto de vista, para efeitos de nossa reflexão, a questão relevante está em saber até que ponto o Brasil se prepara para superar a tradicional estratégia baseada-no-investimento-em-capital-físico (como se fosse suficiente para gerar inovações) e desenvolver uma nova estratégia baseada-na-inovação? Até que ponto os investimentos em infraestrutura, ou mesmo em empresas de porte - mas ligadas à produção 
de commodities -, por necessários que sejam, são capazes de elevar o padrão de competitividade da economia?

As mudanças dos últimos quinze anos e a aceleração do ritmo do crescimento a partir de 2003, apesar de positivos, oferecem apenas uma resposta parcial e insuficiente para essas questões. Se tomarmos a Política Industrial, Tecnológica e de Comércio Exterior (PITCE), anunciada em 2004, como um marco, observamos que a inserção da inovação no centro da agenda de desenvolvimento ajudou, mas esteve longe do satisfatório e, mais ainda, do necessário. Suas diretrizes combinaram políticas de modernização da produção e dos serviços com políticas propriamente voltadas para a inovação. Desse ângulo, a PITCE procurou definir medidas e metas que deveriam ajudar o país a ultrapassar algumas restrições estruturais da economia, de modo a ligar o país ao futuro. Descortinaram, portanto, um caminho capaz de driblar a rigidez do desenvolvimentismo e o estado anestesiado dos anos de 1990. Não teve força nem recursos para se impor, por carência de suporte e legitimidade política para a execução de suas propostas. Nessas condições, a trajetória realizada aproximou-se mais de um processo gradual do que de uma evolução aos saltos, semelhante à experiência dos países asiáticos, descrita por Hobday ${ }^{22}$. Parafraseando o autor, em vez do "pulo do sapo", o setor público e as empresas brasileiras envolveram-se em um longo processo de aprendizagem, doloroso e incremental, semelhante à jornada cadenciada de um "burro de carga". Seécerto que a inovação fincou raízes no panorama econômico e político, consolidando-se alternativa viável entre os policy-makers e alastrando-se como perspectiva no meio empresarial, a incorporação de sua dimensão estratégica está longe de mostrar-se consensual.

Os oito comentários abaixo destacam alguns obstáculos e desafios relativos à inovação e à tecnologia que a economia brasileira não pode ignorar.

1. Foi a partir da PITCE que a inovação começou de fato a freqüentar a agenda das instituições de Estado e a ganhar o apoio do setor empresarial. Do ponto de vista da acuidade e da consistência de seus instrumentos, a PITCE representou apenas um primeiro passo, insuficiente, seja por conta das restrições fiscais, seja por dificuldades político-institucionais relacionadas com a frágil coordenação entre ministérios, agências e à falta de sintonia com o BNDES. Como o principal pilar de sustentação das políticas industriais do país, o BNDES, historicamente, respondeu pelas obras de infra-estrutura, pelo financiamento das grandes empresas e, em sua fase mais madura, das exportações. Sem a pretensão de julgar a trajetória do banco, registramos apenas que o seu modus operandi quase sempre esteve marcado por esses objetivos gerais e por um
[22] "Hard slog rather than a leapfrog" (Hobday, M. Innovation in East Asia. Cheltenham: E. Elgar, 1995, p. 200. 
[23] Lundvall, B. "Innovation as an interactive process: from user-producer interaction to the national system of innovation. In: Dosi, G. e outros (eds.), Technical change and economic theory. Londres: Pinter, 1988.
[24] Acemoglu, D., Aghion, P. e Zilibotti, F. "Distance to frontier, selection, and economic growth". Journal of the European Economic Association, 2006, vol.4, ${ }^{\circ}$ 1, pp. 888-908,p. 889 expressivo viés setorial, uma vez que seus planos incluíam a construção e o fechamento dos elos das cadeias de suprimento, no esforço de equiparação da indústria nacional com a moderna produção estrangeira. Essas características, aliadas a um difuso diagnóstico sobre a necessária mudança de rumo da economia brasileira, dificultaram a plena inserção do BNDES na rota da inovação e da tecnologia. Num certo sentido, o banco ainda se debate com parte dessas dificuldades até os dias de hoje. No ponto de partida da PITCE estava a inovação como um "processo interativo" 23 , capaz de produzire de gerar impactos a partir de uma mal ha de relações avessa à compartimentalização da indústria. Nesse sentido, as tentativas de enquadrar os processos de inovação nas velhas chaves que opunham setores tradicionais aos dinâmicos, ou que encerravam as cadeias produtivas em segmentos estanques, certamente enfrentariam dificuldades. Apesar de fruto do esforço industrializante, $\mathrm{O}$ BNDES avançou consideravel mente na busca de um reordenamento institucional - como o demonstram vários de seus programas que vão além da modernização industrial, ou seu incentivo à formação de um mercado de venture capital. Seu foco setorial e o apego ao investimento como motor da inovação ainda pesam em sua intervenção. A qualificação e a priorização do investimento segundo as necessidades do país - e não apenas das grandes empresas ou do banco - poderia levá-lo a elevar o padrão de seus empréstimos e a utilizar os juros subsidiados para a efetiva diversificação e elevação do padrão de competitividade da economia. À época, nem sempre essas questões foram formuladas com clareza meridiana.

2. Quando a qualidade do investimento é trazida para o centro do debate sobre desenvolvimento, nem sempre a discussão flui com facilidade. As estratégias baseadas no investimento - nem sempre orientadas para áreas, empresas e cadeias de al to valor agregado - , que não perseguem sistematicamente a busca de padrões tecnológicos superiores, correm maior risco de repor alguns dilemas que se arrastam desde o fim do ciclo desenvolvimentista. As estratégias estruturadas em torno da inovação - como as assentadas na PITCE e, posteriormente, na Política de Desenvolvimento Produtivo (PDP) - tendem a superar essas armadilhas. No entanto, serão eficazes apenas se buscarem obstinadamente a implantação de um padrão sustentável de crescimento a partir do avanço tecnológico capaz de aumentar a produtividade da economia. Isso porque uma

[...] economia pode permanecer com uma estratégia baseada no investimento por um período demasiadamente longo. A demora na sua substituição por uma estratégia baseada na inovação reduz o crescimento, pois a economia nãoécapaz de aproveitar todas as oportunidades abertas pela inovação" 24 . 
Em outras palavras, quanto mais uma economia madura se mantiver atrelada ao seu velho padrão de competitividade, maior será o risco de entrar num círculo vicioso que impedirá a sua migração para as áreas tecnológicas mais avançadas. Estudos de De Negrii25 sugerem a existência de uma relação seqüencial entre investimento em P\&D e investimento em capital fixo. A partir de levantamento realizado em um amplo grupo de empresas, sua pesquisa demonstrou que as firmas que investem em P\&D investem 17\% a mais em capital fixo (na média) do que as empresas que não investem em P\&D. Isso significa que o desenvolvimento de processos de inovação possibilitam a formação de ciclos virtuosos para as empresas.

3. Ao acompanharmos a trajetória da PITCE e da PDP, observase que a ênfase na inovação/investimento ganhou enorme importância. $\mathrm{O}$ avanço foi significativo, sem dúvida. No entanto, ao nos debruçarmos sobre esse binômio, notamos que o segundo termo, o "investimento" (especialmente em infra-estrutura e em grandes empresas de commodities), ainda recebe tratamento superior e preferencial quando comparado ao primeiro, a "inovação". Não se trata de uma ênfase apenas discursiva, mas de um diferencial estabelecido de fato em programas, ações e, em última instância, em recursos dos ministérios e do BNDES. Espera-se que, gradualmente, uma relação mais equilibrada venha a ser estabelecida, de modo a superar essa armadilha que não favorece o investimento na elevação do patamar das empresas. Sem resolver esse dilema, o Brasil poderá até mesmo elevar a taxa do investimento agregado, sem que seja superado o peso das commodities na economia.

4. Com a PITCE, foram criados o Conselho Nacional de Desenvolvimento Industrial (CNDI) e a Agência Brasileira de Desenvolvimento Industrial (ABDI). O CNDI, dirigido pelo presidente da República, nasceu para reunir ministros de Estado, representantes de associações empresariais e de trabalhadores, além de outras lideranças da sociedade. AABDI seria sua secretaria executiva, responsável pela coordenação e gerenciamento da nova política industrial lançada em 2004. No entanto, apesar de ter sido criada e estruturada como a celebração de acordo entre o Ministério do Desenvolvimento e o Ministério da Ciência e Tecnologia, os problemas de interação institucional raramente foram resolvidos. Desde a sua criação, a ABDI empenhou-se para delimitar seu espaço institucional. O papel que desempenhou na primeira fase da PITCE, como uma agência difusora de inovação, esvaiu-se ao longo do tempo. Em 2008, após a segunda edição da política industrial (Política de Desenvolvimento Produtivo, PDP), quatro anos após sua criação, a ABDI ainda estava à procura de seu lugar no mapa institucional do Planalto. Dada a forte presença do BNDES na condução da PDP, e diante do crescimento da Finep, o espaço de coordenação da
[25] De Negri, "Trade, innovation and firm growth in Brazil", op. cit. 
[26] Se excluídos os subsídios relacionados com a Lei da informática, cf. Iedi. "Desafios da inovação. Incentivos para inovação:o que falta ao Brasil". São Paulo: Iedi, fev. 2010. política industrial tornou-se menor para a ABDI. Mais importante: $\mathrm{O}$ distanciamento de suas funções originais ligadas à inovação impulsionou a agência em direção ao ativismo de curto prazo, o que não fortalece suas pretensões de coordenação nem torna mais robusta sua institucionalidade. A despeito dos esforços de sua equipe, a agência sofre por carência de suporte político e se vê desamparada na busca de legitimidade institucional.

5. O financiamento à inovação é essencial. Há lacunas e gargalos enormes, tanto na rede de infra-estrutura como nas áreas de pesquisa em fases pré-competitivas das empresas. Não há programas orientados para essa fase pré-comercial no Brasil, atualmente, tampouco instituição responsável por esse tipo de atividade. Nesse sentido, é urgente ampliar o espectro institucional, de modo a consolidar um arco diversificado de apoio às atividades de inovação, desde o diagnóstico, passando pelas fases pré-projeto, projeto, execução, incubação e pósincubação. Sem essa diversidade de instrumentos os esforços de inovação não chegarão até as pequenas empresas, que são fundamentais para liberar o potencial empreendedor da economia.

6. Quando se examina as iniciativas de incentivo a P\&D e à inovação nas empresas, nota-se que apesar dos avanços proporcionados pela Lei do Bem, os incentivos efetivamente concedidos foram baixos. Em 2008, o valor desses subsídios foi de aproximadamente 0,08\% do $\mathrm{PIB}^{26}$. Esse desempenhoé apenas um pouco maior do que o do México $(0,05 \%)$ e muito menor do que o da França $(0,18 \%)$, dos Estados Unidos $(0,22 \%)$ e do Canadá (0,23\%), países com uma estrutura de apoio à inovação muito mais ampla e completa do que a brasileira. A ampliação desse montante é fundamental para a elevação do nível de inovação na economia.

7. A descoberta da camada pré-sal abre uma janela de oportunidades para a Petrobrás e para uma camada imensa de empresas brasileiras desenvolverem atividades tecnológicas de classe mundial. As descobertas do pré-sal, somadas ao potencial de recursos renováveis - especialmente do etanol - , formam uma alavanca poderosa capaz de movimentar um longo ciclo de desenvolvimento. Por isso, é urgente a formulação de uma política industrial para o pré-sal que não se restrinja aos setores de petróleo e gás. Seu escopo é amplo e envolve as engenharias, o desenvolvimento de novos materiais, a nano e a biotecnologia, assim como se estende à indústria aeroespacial e aeronáutica. Escolhas desse tipo dependem da definição de grandes investimentos (do setor público e privado) em $\mathrm{P} \& \mathrm{D}$, de modo a possibilitar que muitas empresas genuinamente brasileiras possam aproximar-se mais rapidamente da fronteira tecnológica. Uma política desse tipo não será realizada sem que as universidades se envolvam e interajam com as empresas. 
8. A universidade brasileira tem papel-chave nesse processo, seja na qualificação de recursos humanos, seja na condução de pesquisas avançadas. É necessário, porém, para o desenvolvimento do país, que ela se reconheça como tal. O esforço para mudar seus hábitos e cultura é essencial, como muitos pesquisadores já se deram conta. É preciso que a universidade se mostre aberta e derrube com sua prática os muros que a separam da sociedade. Não se trata de incorporar uma agenda de Estado, ou de assumir a pauta das empresas. Como instituições distintas, devem desempenhar autonomamente seu papel. Cabe à comunidade acadêmica, porém, refletir sobre sua própria agenda de pesquisa, de modo a entrar em sintonia com os esforços do país. Uma dinâmica interna virtuosa pede a ruptura das comportas departamentais, assim como a abertura da universidade à entrada de novos contingentes da população que buscam na educação e no acesso ao conhecimento disciplinado um ponto de apoio para a elevação de seu padrão de vida. $\mathrm{Na}$ área de recursos humanos reside um dos maiores, senão o maior gargalo da inovação no Brasil. A escassez do trabalhador de alta qualidade está na raiz do baixo nível de inovação e produtividade nas empresas. A inovação é atividade de encruzilhada, multidisciplinar por excelência. Inovação na universidade é produção de conhecimento novo, que se dá, nos tempos atuais, a partir do entroncamento de disciplinas. A diversificação, a abertura para a sociedade e a integração da prática universitária é chave para o reequacionamento institucional da universidade.

\section{CONCLUSÃo}

O foco na inovação empresarial é crucial para viabilizar um salto da CT\&I brasileira. Novas políticas e instrumentos promoveram avanços institucionais importantes nos últimos quinze anos. A maior presença e intensidade da ação estatal a partir de 2003, ainda que sem o intervencionismo anterior, abriu um capítulo novo na construção de uma estratégia baseada-na-inovação. Os sinais da nova estratégia ainda são ambíguos, mas os processos em curso estão longe de seu desenlace.

O Brasil precisa de um choque de inovação. Isso é ainda mais verdadeiro diante dos avanços da China e da Índia no cenário mundial.

Para acelerar e dar maior consistência a esse processo, sugerimos a criação de uma super Agência de Inovação, dedicada ao desenvolvimento, à coordenação e à implementação de políticas voltadas para a elevação do patamar de competitividade da economia brasileira. Uma nova agência poderá construir uma nova forma de governança da inovação, com foco preciso e vinculação direta com a presidência da República, seguindo os exemplos bem-sucedidos de vários países. Não apenas a ABDI e a Finep seriam partes constituintes dessa nova Agência, 
[27] Nelson, R. "The challenge of building na effective innovation system for catch-up". Oxford Development Studies, 2004, vol. $32, \mathrm{n}^{\circ}$, pp. 365-74, pp. 365-68.

[28] Nelson, R.e Sampat, B. “Making sense of institutions as a factor shaping economic performance". Journal of Economic Behavior and Organization, 2001, vol. $44, \mathrm{n}^{\circ} 1, \mathrm{pp} .31-54$.

Recebido para publicação em 21 de junho de 2010 .

\section{NOVOS ESTUDOS}

CEBRAP

87 , julho 2010

pp. 13-33 como sairiam fortalecidas a partir desse reordenamento institucional: uma Agência com orçamento potencializado, programas e recursos humanos qualificados. A estreita proximidade com a presidência da República ajudaria a conferir legitimidade para o desenvolvimento do diálogo interno e externo ao governo necessário, a começar do empresariado e das universidades.

Foi-se a época em que Brasília poderia pensar as políticas de tecnologia sem a ativa participação das partes interessadas nesse processo, a começar de empreendedores, empresariados e pesquisadores. Não se trata apenas de uma preocupação com parceiros, mas do reconhecimento de que a inovação em grande escala demanda habilidades e saberes diferentes, que nenhum agente, público ou privado, pode isoladamente fornecer.

Ao analisar as dificuldades que muitas economias em desenvolvimento encontraram para desenvolver seus processos de catch up, Nelson destacou que "tecnologias sociais são mais difíceis de adquirir do que as físicas" 27. Para o autor, as "tecnologias sociais" estão enraizadas em valores, formas organizacionais, sistemas de incentivo, regras, rotinas administrativas e políticas públicas ${ }^{28}$. Práticas construídas ao longo de décadas permeiam as instituições e fazem parte da rede de relações que dirigem seus mecanismos. Muitas orientam-se pela racionalidade do governo. Outras estão revestidas pelo manto das relações de poder, dos interesses, ideologias e até mesmo das paixões. São esses fatores queestão na raiz do funcionamento desarticulado das agências estatais e dos ministérios. Nesse nível, a força da política não deve ser subestimada. Poderá ser de extrema valia na busca do fortalecimento institucional que o Brasil precisa para consolidar um sistema nacional de inovação ancorado numa economia inovadora.

GLAUCO ARBIX é professor do Departamento de Sociologia da USP, coordenador-geral do Observatório da Inovação do Instituto de Estudos Avançados (USP) e membro do Conselho Nacional de Ciência e Tecnologia. 